\title{
Correction: Molecular crosstalk between ferroptosis and apoptosis: Emerging role of ER stress-induced p53-independent PUMA expression
}

\author{
Se Hoon Hong ${ }^{1, *}$, Dae-Hee Lee ${ }^{2,3, *}$, Young-Sun Lee ${ }^{1}$, Min Jee Jo ${ }^{2}$, Yoon A Jeong ${ }^{2}$, \\ William T. Kwon ${ }^{1}$, Haroon A. Choudry ${ }^{1}$, David L. Bartlett ${ }^{1}$ and Yong J. Lee ${ }^{1}$ \\ ${ }^{1}$ Department of Surgery, School of Medicine, University of Pittsburgh, Pittsburgh, PA 15213, USA \\ 2 Brain Korea 21 Program for Biomedicine Science, Korea University College of Medicine, Korea University, Seoul 02841, \\ Republic of Korea \\ ${ }^{3}$ Division of Oncology/Hematology, Department of Internal Medicine, College of Medicine, Korea University Medical Center, \\ Korea University, Seoul 08308, Republic of Korea \\ * These authors have contributed equally to this work \\ Published: May 15, 2018
}

Copyright: Hong et al. This is an open-access article distributed under the terms of the Creative Commons Attribution License 3.0 (CC BY 3.0), which permits unrestricted use, distribution, and reproduction in any medium, provided the original author and source are credited.

This article has been corrected: The correct Figure $2 \mathrm{C}$ is given below:

The authors declare that this correction does not change the results and conclusions of this paper.

C
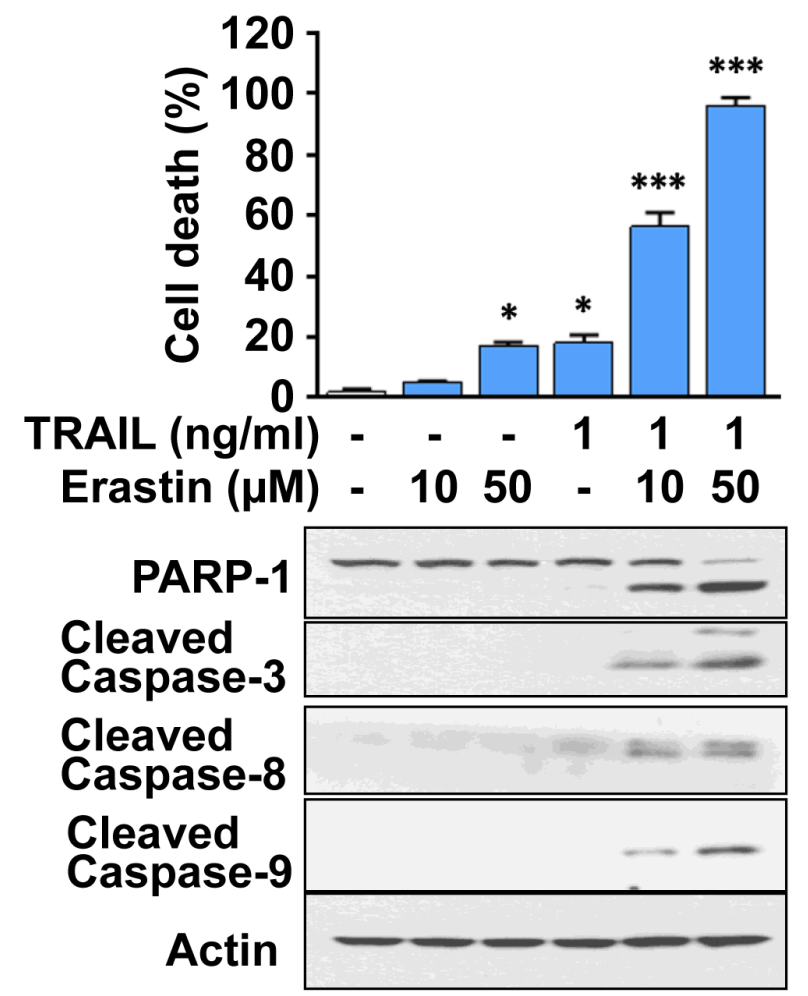

HCT116

Figure 2: Erastin promotes TRAIL-induced apoptosis. C. HCT116 cells were pretreated with erastin $(10$ or $50 \mu \mathrm{M})$ for $20 \mathrm{~h}$ and then exposed to TRAIL $(1 \mathrm{ng} / \mathrm{ml})$ for an additional $4 \mathrm{~h}$. Cell death was determined using trypan blue exclusion assay. Whole-cell extracts were then analyzed with immunoblotting assay using indicated antibodies. 